\title{
Surgical treatment of gynaecomastia: a standard of care in plastic surgery
}

\author{
Tobias R. Mett ${ }^{1}$ (D) Peter P. Pfeiler ${ }^{1} \cdot$ Rosalia Luketina $^{1} \cdot$ Alperen S. Bingöl $^{1} \cdot$ Nicco Krezdorn ${ }^{1} \cdot$ Peter M. Vogt $^{1}$
}

Received: 14 August 2019 / Accepted: 18 December 2019/Published online:22 January 2020

(C) The Author(s) 2020

\begin{abstract}
Background Many techniques for the surgical treatment of gynaecomastia have been reported to be effective with reasonable limited scar formation. The aim of this study was to develop a grade adopted algorithm for effective and scar sparing techniques in reconstruction of the male breast dependent on aetiology and grading.

Methods Operative techniques, results, rates of revisions and complications were recorded between 2006 and 2018 and results of 164 male patients were analysed, retrospectively. Skin resecting methods have been used in the earlier stage but were later replaced by minimal periareolar incisions and subcutaneous mastectomy. Resections were combined with ultrasound-assisted liposuction up to grade $2 \mathrm{~b}$ and inferior pedicled breast reduction in 3rd degree gynaecomastias resulting in reduction of scars and effective removal of breast tissue.

Results Retrospective analysis showed that a periareolar mastopexy was used in $24 \%$ of patients with gynaecomastia grade I, IIa and IIb to reshape the breast after subcutaneous mastectomy in the early stage of this study from 2006 to 2010 . With the established standardised use of ultrasound-assisted liposuction, only $2 \%$ of patients required a mastopexy in the following years. In grade 3 gynaecomastia, the classical approach resulting in an inverted t-scar was later abandoned for an approach with a periareolar and submammary scar and inferior dermoglandular flap. The rate of secondary surgery with the used techniques did not increase.
\end{abstract}

Conclusions When using standardised techniques in reshaping the male breast, an aesthetically pleasing and safe result can be achieved by scar sparing techniques in a safe single-stage procedure.

Level of evidence: Level IV, therapeutic study.

Keywords Gynaecomastia $\cdot$ Male breast $\cdot$ Scar sparing $\cdot$ Inferior pedicle $\cdot$ Massive weight loss $\cdot$ Breast reduction

\section{Introduction}

The restoration of gender conformity of the chest wall is the fundamental desire of the male patient and the fundamental goal in treatment of gynaecomastia.

Shaping of the body is a rising issue for men and includes breast reduction procedures besides liposuction and facial surgery. The number of surgical treatments of gynaecomastias and pseudogynaecomastias has increased

Tobias R. Mett and Peter P. Pfeiler contributed equally to this work.

Tobias R. Mett

tobias.mett@gmail.com

1 Department of Plastic, Aesthetic, Hand and Reconstructive Surgery, Burn Center, Hannover Medical School, Carl-Neuberg-Str.1, 30625 Hannover, Germany by more than $30 \%$ in the last 17 years [1]. Breast reduction has become one of the top 5 procedures in plastic surgery over the last decade [1].

Gynaecomastia and pseudogynaecomastia are two entities of increasing male breast volume with or without skin excess and may occur bi- or unilaterally. Typically, the first episode in life comes along with a high prevalence of gynaecomastia in up to $90 \%$ of neonates [2]. The following decades show two peaks for adolescents and elderly men with a range of prevalences from 50 to $70 \%$ [3-9].

Previous studies indicated that there was no correlation between gynaecomastia and breast cancer. Incidences vary from $0.5-1.5 \%$ in men with gynaecomastia [10-12]. Since an unexpected growth of tissue is always suspect to arise from a malignant tumour, clinical examination, detailed history and imaging are mandatory for any diagnosis. If the clinical appearance is not suspect for cancer, different therapeutic options can be chosen. 
For patients with a history shorter than 6 months, a watchful wait-and-see strategy should be the first choice. Depending on its trigger medical treatment may be indicated and lead to successful reduction of breast volume by correcting hormonal disarrangements or blocking proliferative pathways in florid tissue $[13,14]$. Recently, published data showed a high effectiveness for tamoxifen with moderate side effects [15]. However, this approach will not work in fibrotic tissue and thus may not be applicable in many cases.

Surgery has been shown to be an effective and well accepted treatment for gynaecomastia persisting over 6-12 months without signs of regression. Over the last decades, multiple classifications and techniques have been developed with more or less distinct advantages. Until today no evidence-based algorithm exists for the surgical treatment. However, a stagebased approach is widely accepted. In 1944, Webster offered a classification in relation to the tissue characteristics [16]. Including the pseudogynaecomastia with pure fat two other subtypes had to be differentiated in mixed fat and glandular tissue and an all glandular hypertrophy. A more adaptive system was introduced in 1973 by Simon that is preferred and used by us [17]. The first degree is a non-visible but palpable enriched glandula, which may be painful during palpation. The next degree is separated in $2 \mathrm{a}$ and $2 \mathrm{~b}$ with an obvious but moderate hypertrophy of breast tissue without (grade 2a) or with (grade $2 b$ ) skin excess. A feminine appearance with a lot of excessive skin, formation of a submammary fold and ptotic breast is summarised as third degree gynaecomastia (Fig. 1).

With this study, we present our results of the last 12 years, showing an evolution of surgical management avoiding complications and reducing the role of secondary surgery. We suggest a distinct algorithm for the surgical treatment of gynaecomastia and pseudogynaecomastia to reach the basic goal of scar sparing and effective restoration of a gender matching phenotype (Fig. 1).

\section{Material and methods}

Patient records and images from the clinical database were evaluated between the years 2006 and 2018. A total of 164 patients have been treated for gynaecomastias from grade I to III according to the grading of Simon. Patient records included the first consultations, operation reports, discharge letters and notes of postoperative check-ups. Patients were called in 6 weeks postoperatively for a clinical re-evaluation and for photographic documentation. To detect changes of the internal protocol a separation into three timeframes of 4 years each was done.

The study was approved by the clinical ethics committee of the Hannover Medical School (No. 8191 BO K 2018). The inclusion of the subjects was done by a retrospective retrievement from the clinical database without any possible influences and invasiveness of the subjects. Data were analysed anonymously. Informed consent for the use of data and photographs for scientific purposes was given by each patient. The study conforms to the provisions in accordance with the Helsinki Declaration (revised in 2013).

\section{Operative strategy}

For gynaecomastia grade 1 and $2 \mathrm{a}$ according to Simon we used the subcutaneous mastectomy (SCM) approaching through the semilunar incision in every case. Since ultrasound-assisted liposuction was introduced in 2005 liposuction was used routinely for additional contouring or in cases of pseudogynaecomastia. Larger amounts of skin excess as they could be found in $2 b$ grades were initially treated by periareolar pexies (PAP), in the first period. Breast reductions of 3 rd degree gynaecomastias have been treated by classical approaches with resulting inverted t-scars in the beginning and were later replaced by the inferior pedicled technique after Kornstein [18].

\section{Surgical technique}

An infiltration of tumescence solution consisting of $20 \mathrm{ml}$ bicarbonate, $1 \mathrm{mg}$ adrenaline in $1000 \mathrm{ml}$ sodium was performed in every subcutaneous mastectomy. In grades $1-2 b$ we approached the gland through a semilunar incision at the lower areola margin to preserve the aesthetic unity of the nipple-areola complex (NAC) and ensure an inconspicuous placement of the scar (Fig. 2). By this approach the Cooper-ligaments can be released by palpation and a stepwise preparation with a scissor or bipolar scissor to the pectoral fascia is allowed. The gland is held by a Kocher-Clamp until the mobilisation is completed circumferentially and an extirpation in toto is possible. To prevent aesthetically unpleasing retraction of the areola a proper disc underneath the areola has to be preserved. Since the tissue of gynaecomastias often is a mixture of fibrotic gland and subcutaneous fat a combination of subcutaneous mastectomy and ultrasound-assisted liposuction was performed routinely (Fig. 3). For ultrasound-assisted liposuction (UAL) Sonoca ${ }^{\circledR}$ 400 from Soering (Sonoca ® 400, Soering, Quickborn, Germany) with a frequency of $25 \mathrm{kHz}$ and a suction of $0.6 \mathrm{bar}$ were applied using hollow titanium cannulas of $3.3 \mathrm{~mm}$ for contouring or $4.5 \mathrm{~mm}$ for deep layered fat and re-movement of higher volume. Suctions drains were placed in every case.

Skin excising techniques have been reserved for $2 b$ and $3 r d$ degree gynaecomastias and for cases with a high amount of skin excess, as they can be seen in post-bariatric patients. Concentric or eccentric excision, resecting periareolar skin using the technique of Huang and Benelli $[19,20]$ were performed for 2bdegree gynaecomastias or persisting skin excess after subcutaneous mastectomy in the earlier stage (Fig. 7). In 3rd degree 


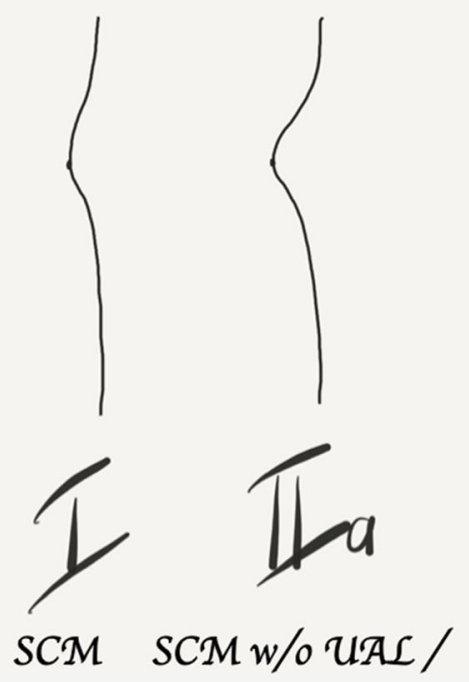

Fig. 1 Schematic treatment algorithm of stage-adapted surgical treatment of gynaecomastia adapted from Simon's grading. Grade I shows almost no extra volume but pain and a little gland an usually needs a subcutaneous mastectomy (SCM). Grade IIa has a visible plus of volume without skin excess and thus may be complemented with or without ultrasound-

gynaecomastias and pseudogynaecomastias, we used an inverted $\mathrm{t}$-scar approach with a superomedial pedicle for the nipple-areola complex (NAC) but replaced this technique by the NAC bearing inferior pedicle with a single scar in the submammary fold (Figs. 4, 5, 6, and 7). After de-epithelialisation of the pedicle a superior incision allowed broad access to remove excessive breast tissue and skin. A wide base of the pedicle about 8 $10 \mathrm{~cm}$ has been preserved, allowing a sufficient thinning of up to $0.5 \mathrm{~cm}$ without compromising the NAC's perfusion (Fig. 4). The pedicle was fixed to the chest wall using some resorbable sutures. The reinsertion of the NAC followed the Mohrenheimestimated-tangential-tracking-line (METT-Line) using a vertical line from the notch of Mohrenheim as a lateral margin of the areola, placing it $4-4.5 \mathrm{~cm}$ above the resulting submammary fold (Figs. 5 and 6) [21].

\section{Statistical tools}

Microsoft Office Excel 2010 (Microsoft Corp, Redmond, WA) was used for data collection as well as for descriptive statistical analysis.

\section{Results}

Research of all male patients undergoing a mastectomy, breast reduction and liposuction of the chest wall between 2006 and 2018 were reviewed. In 12 years 164 consecutive patients were treated for gynaecomastia in the Department of Plastic, Aesthetic, Hand and Reconstructive Surgery of the Hannover Medical

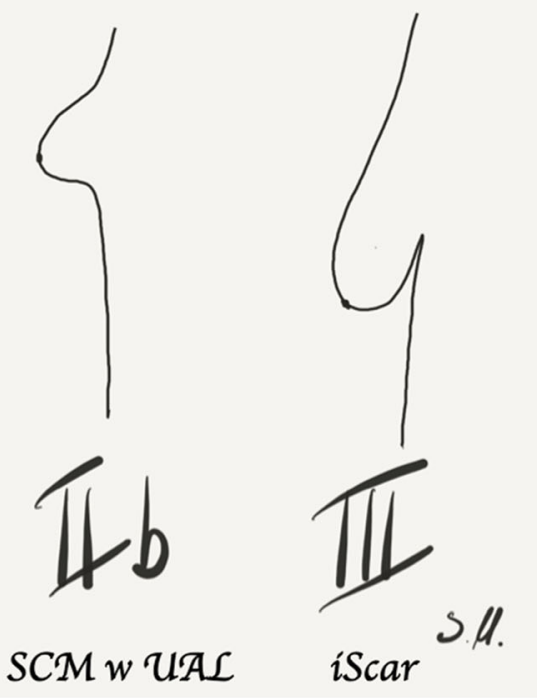

assisted liposuction (UAL). This is typical for Grade IIb with an almost female aspect and an enlarged areola needing the combination of SCM and UAL routinely. Grade III is defined by excessive skin, soft tissue and ptosis and should be treated with an inferior pedicled or free grafted NAC and single inferior scar approach (iScar) in the submammary fold.

School. A total of 297 male breasts included 133 bilateral und 31 unilateral gynaecomastias and pseudogynaecomastias. Patient ages ranged from 13a to $69 \mathrm{a}$ (mean 25.6a).

As mentioned before, a separation of three groups was made due to technical changes and ongoing improvement of postoperative results.

Group 1 from March 2006 to March 2010 included 54 patients. Grades I and IIa after Simon were treated with subcutaneous mastectomy (SCM) with $(n=21 / 39 \%)$ or without ultrasound-assisted (UA) liposuction $(n=19 / 35 \%)$. Gynaecomastias with skin excess grading of IIb after Simon were routinely operated with a SCM and periareolar pexy (PAP) after Benelli. This was performed in 13 cases $(24 \%)$. UA liposuction was used for additional shaping in $12 / 13$ cases. Grad III gynaecomastia was treated with classical breast reduction resulting with inverted t-scars in 1 patient $(2 \%)$. The mean duration of operation was $113.5 \mathrm{~min}$.

In Group 2 from April 2010 to March 2014, a total of 67 patients were included. As a result of good clinical practice and evaluation of preliminary results of previous patients we changed the internal protocol of gynaecomastia treatment with avoidance of PAP and using the inferior pedicled breast reduction after Kornstein without a vertical scar. Grades I, IIa and IIb received a subcutaneous mastectomy with or without UAL from now on. This included single UAL for breast reduction in 6 cases $(9 \%)$ of pseudogynaecomastia or corrective secondary surgery. Desiring a scar sparing approach gynaecomastias of grad IIb with moderate skin excess underwent SCM with UAL as with the lower grades. Thus, an increasing number of these procedures were performed on 
Fig. 2 Gynaecomastia grade 2a with excess of glandular tissue (a, b). Early postoperative aspect after 2 weeks after release of postoperative taping, treated with subcutaneous mastectomy $(\mathbf{c}, \mathbf{d})$
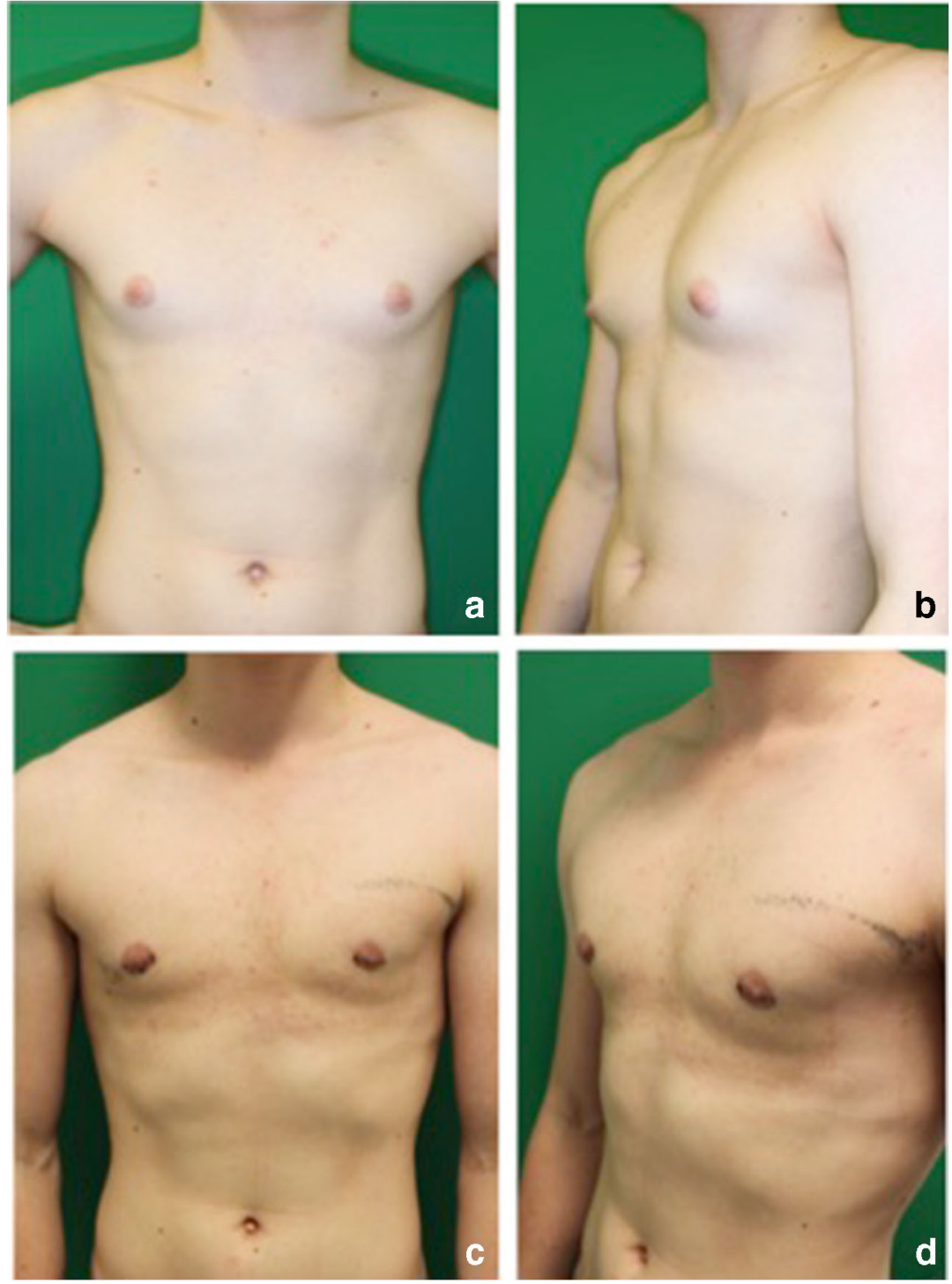

35 patients (52\%). Single SCM were done in 16 cases (24\%). PAP was performed on 4 patients $(6 \%)$ whereas one was a secondary surgery. 6 patients $(9 \%)$ with IIIrd degree gynaecomastia received an inferior pedicled breast reduction (iPed/ iScar) prior to our changing of this approach. In this cohort the mean duration of operation was $106.7 \mathrm{~min}$.

Group III included 43 patients operated from 04/2014 to 03/2018. However, gynaecomastias of Ist and IIa degree underwent a classic SCM $(n=22 / 51 \%)$. Complementary 3 (7\%) pseudogynaecomastias were treated with UAL. The population with IIa and IIb degree gynaecomastia with more or less skin excess was treated with SCM and UAL $(n=9 /$ $21 \%)$ while only $2(5 \%)$ patients underwent a PAP. Third degree gynaecomastias were found in $7(16 \%)$ cases and were consequently operated by the previous described technique leaving a horizontal scar on the level of the submammary fold. During this period the mean operation time was $128.7 \mathrm{~min}$. The results are summarised in Table 1 .
The majority of gynaecomastia was graded IIa after Simon. In this group the standard of SCM leads to reasonable results. Due to the development of ultrasound-assisted liposuction the rate of PAP could be reduced from 24 to $5 \%$. The treatment of third degree gynaecomastias changed completely from inverted t-scars to single horizontal scars preserving aesthetical unions at the male chest wall.

To avoid seromas a compression dressing or garment for 6 weeks was recommended for all patients.

Major complications needing an operative revision were observed in $2 \%(n=3)$ due to bleedings. All other complications $(n=5 / 3 \%)$ were treated conservatively and included partial malperfusion of the NAC $(n=2)$, soft tissue infection $(n=$ 2) and one iatrogenic burn at the abdominal wall during the operation. No significant change of the complication rate could be found for the observed period. Secondary surgery was indicated in $6 \%(n=10)$. One verified recurrence of glandular tissue led to a second SCM. The histological finding of 
Fig. 3 Gynaecomastia grade $2 b$ with redundant skin and excess of glandular tissue (a, b).

Postoperative aspect after

2 months, treated with

subcutaneous mastectomy and ultrasound-assisted liposuction with good skin retraction and almost invisible scars $(\mathbf{c}, \mathbf{d})$
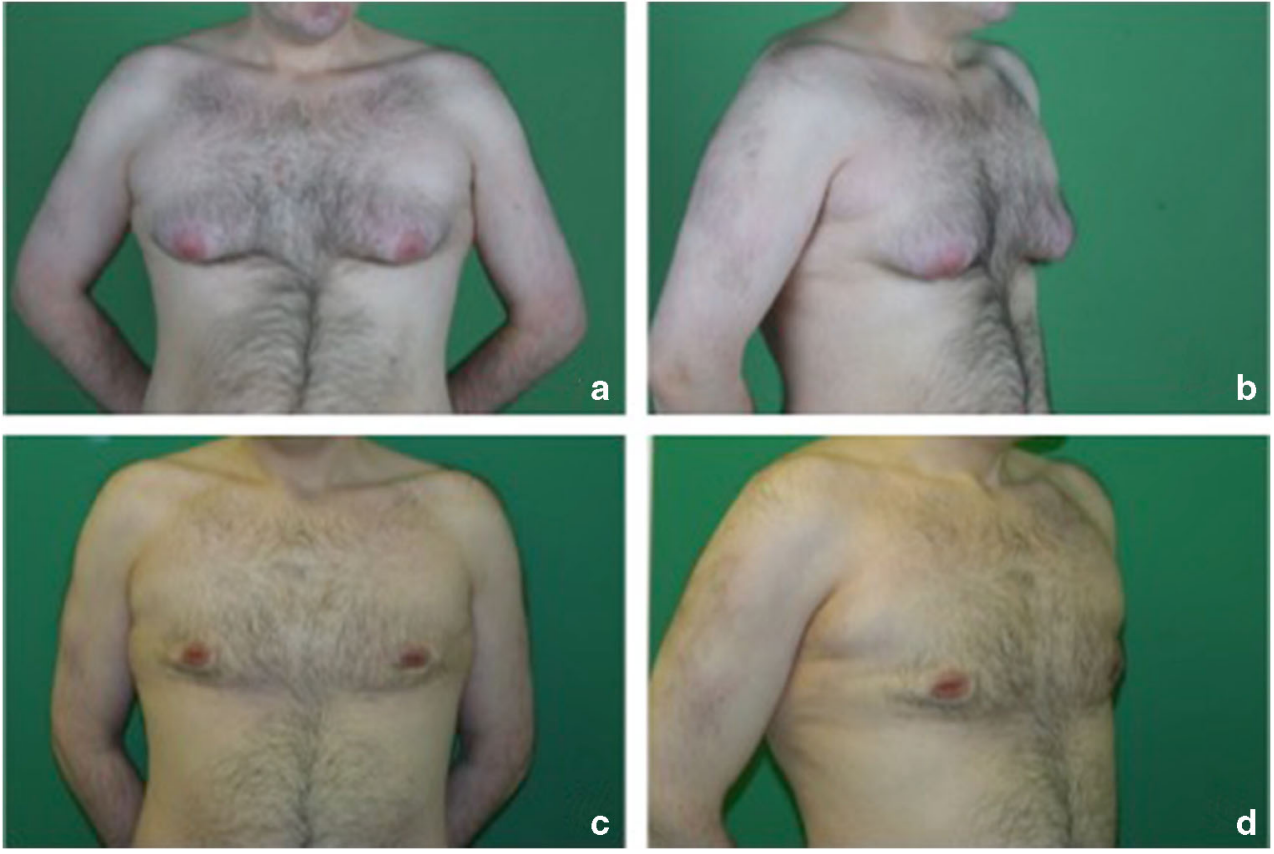

the first treatment showed a florid gland whereas this changed to a fibrotic gland after the second intervention. As mentioned earlier, one patient asked for a NAC pexy and skin tightening, which lead to a PAP. The other 8 cases of secondary surgery were mainly corrective liposuctions of asymmetries or aesthetically unpleasant irregularities. An open approach was used in $3 / 8$ cases to address focal volume disturbances. The incidence of incidental breast cancer was $0 \%$.

\section{Discussion}

It is a standard of care in the field of plastic surgery to use scar sparing and effective methods. This applies without exception for mastectomy and breast reduction in male patients. If gynaecomastia is resistant to medication and persists for more than 6-12 months a surgical correction should be considered. As historical records show Paulus Aegineta already performed a male breast reduction through a semilunar incision in the seventh century [22]. Numerous techniques to restore the male chest wall have been described in the past. The main differences exist in the course of the incision and additive modalities like liposuction resulting in different positioning and length of the scars.

As standardised method the subcutaneous mastectomy is well accepted for 1st and 2a degree gynaecomastias. The incision can be placed around the areola margin or horizontal through the mammillary. To preserve the aesthetic unit of the nipple-areola complex (NAC) and avoid potential paraesthesias, we use semilunar incisions in the lower margin of the areola only. Sufficient treatment of $2 \mathrm{~b}$ graded gynaecomastias may be challenging with respect to a scar sparing and effective approach. As Inocenti et al. showed, the technique of mastectomy should alter depending on the gynaecomastia grading as well as in different body types with satisfying results in the short and long term evaluation [23]. In line with our approach in the first cohort a circumareolar incision in $17 \%$ was used, as we did it in $24 \%$. After internal reviewing of the resulting scars and potential complications with partial or full NAC loss we decided to change the internal protocol and adopted the SCM with UAL to gynaecomastias with moderate skin excess. This may temporarily lead to persisting skin excess directly postoperative but will diminish after 6-12 weeks (Fig. 3). At that time we informed patients about these distinct circumstances and that secondary surgery could be performed if required. Since only $6 \%$ of the patients underwent secondary surgery of which only one patient received a skin reduction, the procedure was implemented as standard treatment of $2 \mathrm{~b}$ gynaecomastias.

With the development of liposuction different modalities showed good results using water assisted, laser assisted or ultrasound-assisted liposuction (UAL) [24]. We recommend using UAL because it releases the density of fibroconnective tissue and thus may remove residual parenchymal tissue and fat after mastectomy [25]. Furthermore, the alteration of the subdermal layer with ultrasound will lead to a sufficient postoperative skin retraction [26]. In support of this, Bailey et al. changed their approach as well when using mainly UAL combined with a pull through technique of the residual tissue with success even with higher amounts of skin excess [27]. In contrast to our study histological examination was not done in those cases.

Technical considerations as liposuction only or liposculpture through axillary, minimal invasive approaches as demonstrated by Lee et al. [28] has the weakness of minor control on re-movement of glandular tissue and missing 
Fig. 4 Secondary 3rd degree gynaecomastia due to adjuvant anti-hormone treatment for prostate cancer, preoperative aspects. a, b Intraoperative situation while breast reduction with an inferior NAC bearing pedicle. $\mathbf{c}$

Preoperative markings defining of the amount of skin excess and additional fat pads in the axillary folds that were addressed with UAL. d Situation after deepithelialisation and resection of excessive tissue with a thin inferior pedicle held in the forceps. A drain has already been placed. $\mathbf{e}$ Simulation of the placement of the pedicle at the chest wall. f The pedicle has been fixed by four resorbable sutures to the chest wall. Postoperative results after 4 weeks with restored masculine breast shape and good wound healing $(\mathbf{g}, \mathbf{h})$
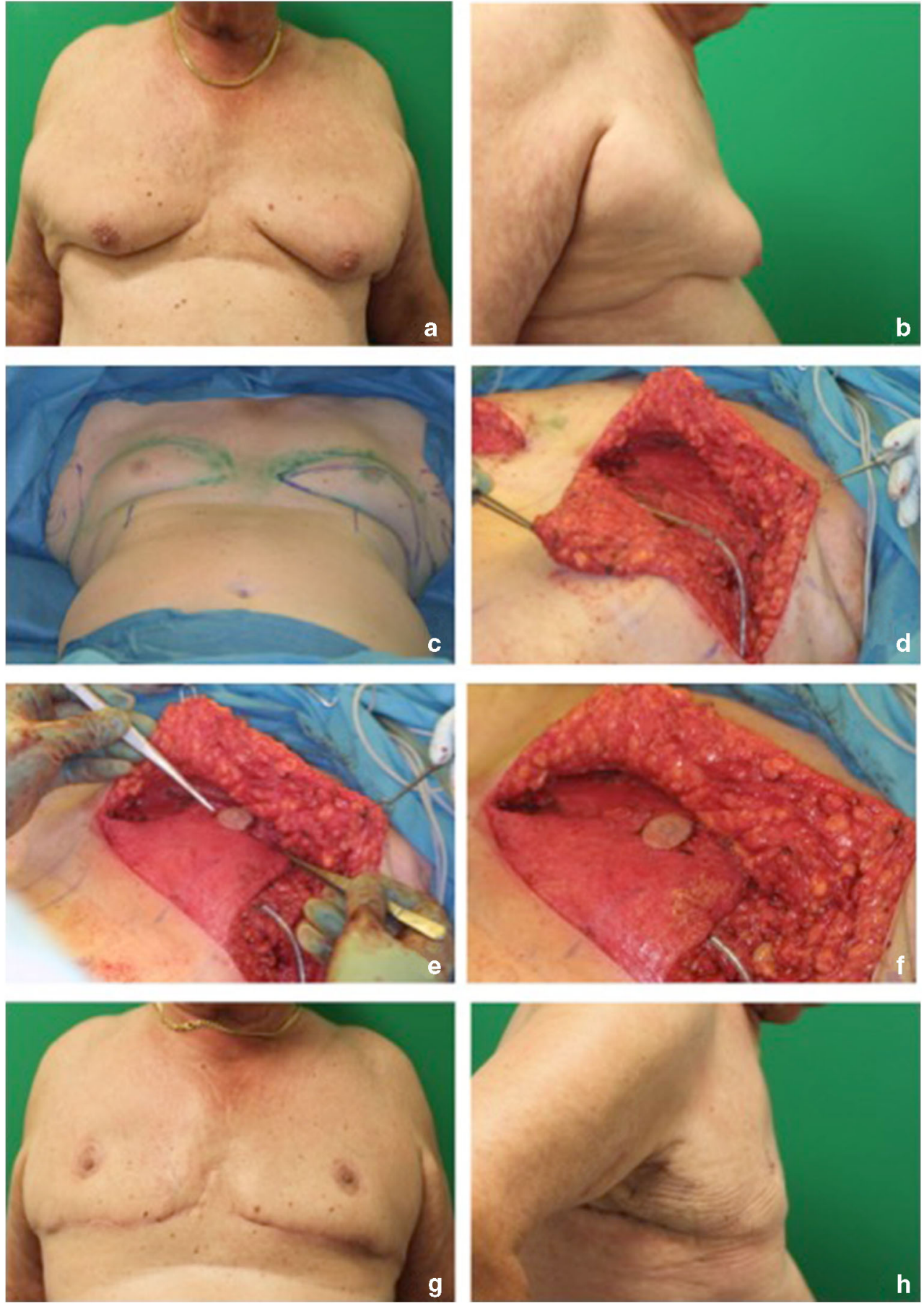

specimens for histological evaluation. Even though breast cancer is rarely found with an incidence of $1 \%$ as stated in 2006 by Fentiman et al., it has to be excluded in every case of untypical tissue growth $[10,29]$. Therefore, we recommend single liposuction for pseudogynaecomastias, only.

High-grade gynaecomastia, massive weight loss patients and transsexual patients have different requirements achieve the desired appearance compared to female patients demanding breast reduction. Thus, a different technique should be used for male breast reduction in high-grade gynaecomastias and massive weight loss patients. Numerous techniques, formulas and approaches have been published for reduction mastopexy in female patients [30]. Inverted t-scars should be avoided due to the prominent resulting scars and different demands of volume and shape (Fig. 7). Kornstein et al. introduced a technique using an inferior broad but thin de-epithelialised pedicle bearing the NAC and preserving a vital and homogenous base for the superior skin flap [18]. Other approaches are applicable such as the lateral chest lift 
Fig. 5 Intraoperative situation of a massive weight loss patient receiving a breast reduction with an inferior NAC bearing pedicle. a Preoperative markings defining the amount of skin excess and the relevant anatomical landmarks. b A thin inferior NAC bearing pedicle is held in the forceps. $\mathbf{c}$ Defining the NAC position 4 $5 \mathrm{~cm}$ above the scar/submammary fold along the Mohrenheimestimated-tangential-tracking line [21]. d Wound closure of the submammary fold and preparation for the reinsertion of the $\mathrm{NAC}$ according to previous measurements
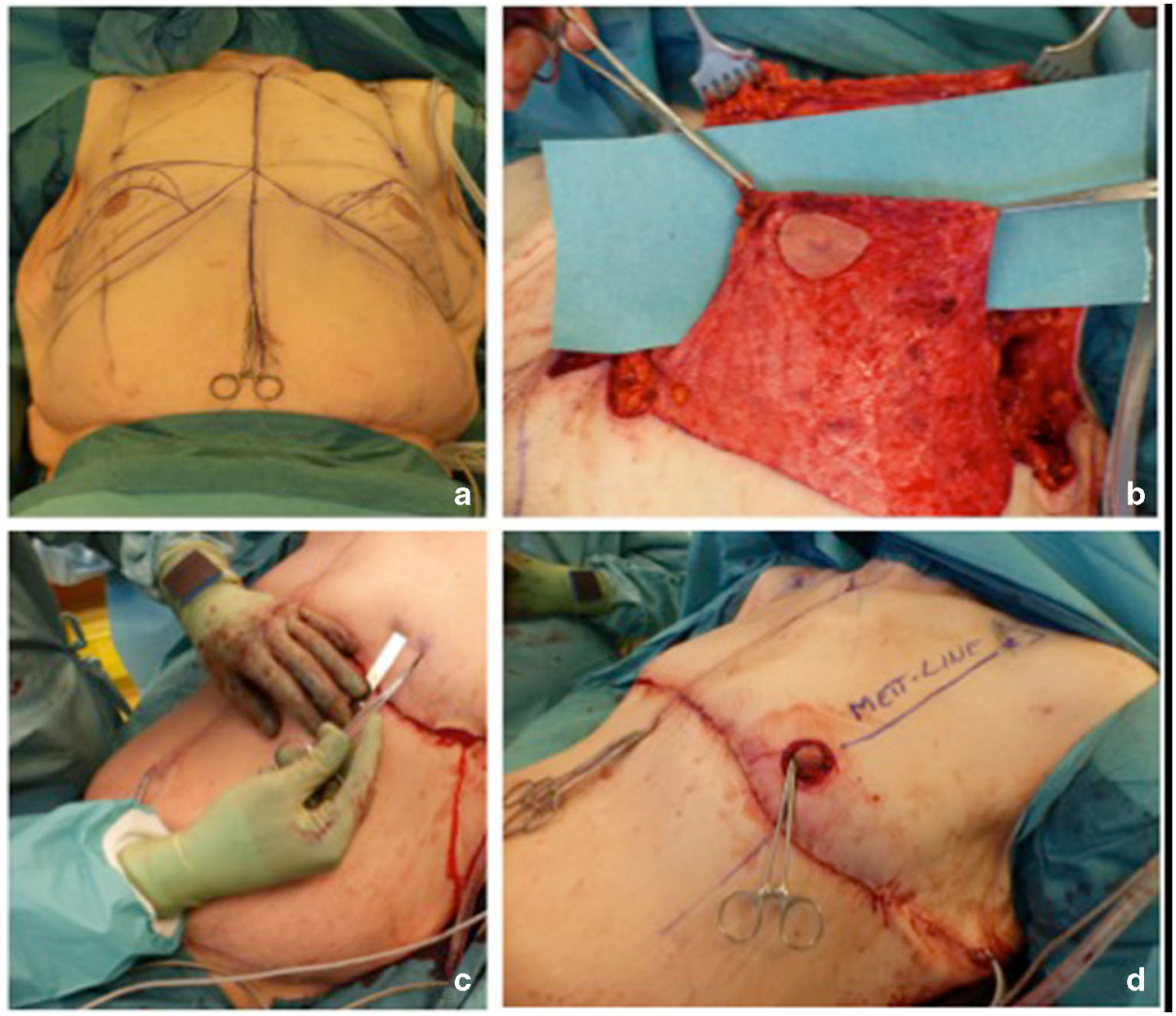

or boomerang pattern reduction [31, 32]. In our routine we prefer to place the resulting scars following inferior pedicled breast reduction in the submammary fold and this is well accepted by the patients (Fig. 6). This method has already been proven to be satisfying for patients in a recent study of Thiénot et al. using this technique as posteroinferior pedicle with small modification to the original procedure [33]. However, the inferior pedicle might be limited to high-grade gynaecomastias and massive weight loss patients with an infra mammary-to-nipple distance up to $10 \mathrm{~cm}$. Larger skin excess might lead to compromised perfusion of the NAC and an unpleasant redundant volume of the pedicle. In these cases an amputation with a free NAC graft is recommended [34]. This was not necessary for our patients.

As with every invasive technique, the operative treatment of gynaecomastia bears the chance of major and minor complications. In the literature a broad range from 3 to $28 \%$ can be found with predominating hematomas and seromas [20]. Our results showed that effective and safe techniques have been employed resulting in a total of $5 \%$ of complications of which only $2 \%$ required a revision in cases of postoperative bleedings and have been classified as major complications. The increased occurrence of bleedings might be due to the higher number of subcutaneous mastectomies in the third period, which carries a higher risk of invisible bleedings due to the minimal invasive approach. Unfavourable soft tissues complications like NAC necrosis and superficial infections could be ruled out by avoiding circumareolar approaches. Although the resultant scarring might be very bothering for the patients, these complications were classified as minor complications due to conservative treatment options. Taking into account that $6 \%$ asked for corrective secondary surgery, a maximum of $11 \%$ may be considered as complications. However, this is in line with recent research [20, 23, 35]. One validated recurrence led to a second SCM 1 year postoperative after resection of a florid gland. While SCM is not intended to be radical in an oncological manner, glandular tissue is always left behind the NAC and usually reaches the margins of the specimen. The low incidence of recurrences is due the proliferative status of the gland which is more often fibrotic as Fricke et al. showed in 555 operated male breasts [36]. Hence, a florid gynaecomastia is more likely to enable recurrent tissue growth.

There are a few weaknesses of this study that need to be mentioned. First, the retrospective design without an ongoing prospective control may lack evidence for superiorities of one technique over another. Nevertheless, as mentioned before, we have a permanent internal review approach of the outcomes that enforced us to adopt techniques during the observed period. The small number of patients did not allow for a powerful statistical significance analysis of complications or advantages of one method. As the Statistics of the American Society of Plastic Surgeons of 2017 showed, only $8 \%$ of all aesthetic procedures 
Fig. 6 Massive weight loss patient with high degree of $\sin$ excess, comparable with 3rd degree gynaecomastia $(\mathbf{a}, \mathbf{b})$. Postoperative results 3 months after breast reduction with inferior pedicled NAC shows moderate scarring and satisfying shaping of the chest $(\mathbf{c}, \mathbf{d})$
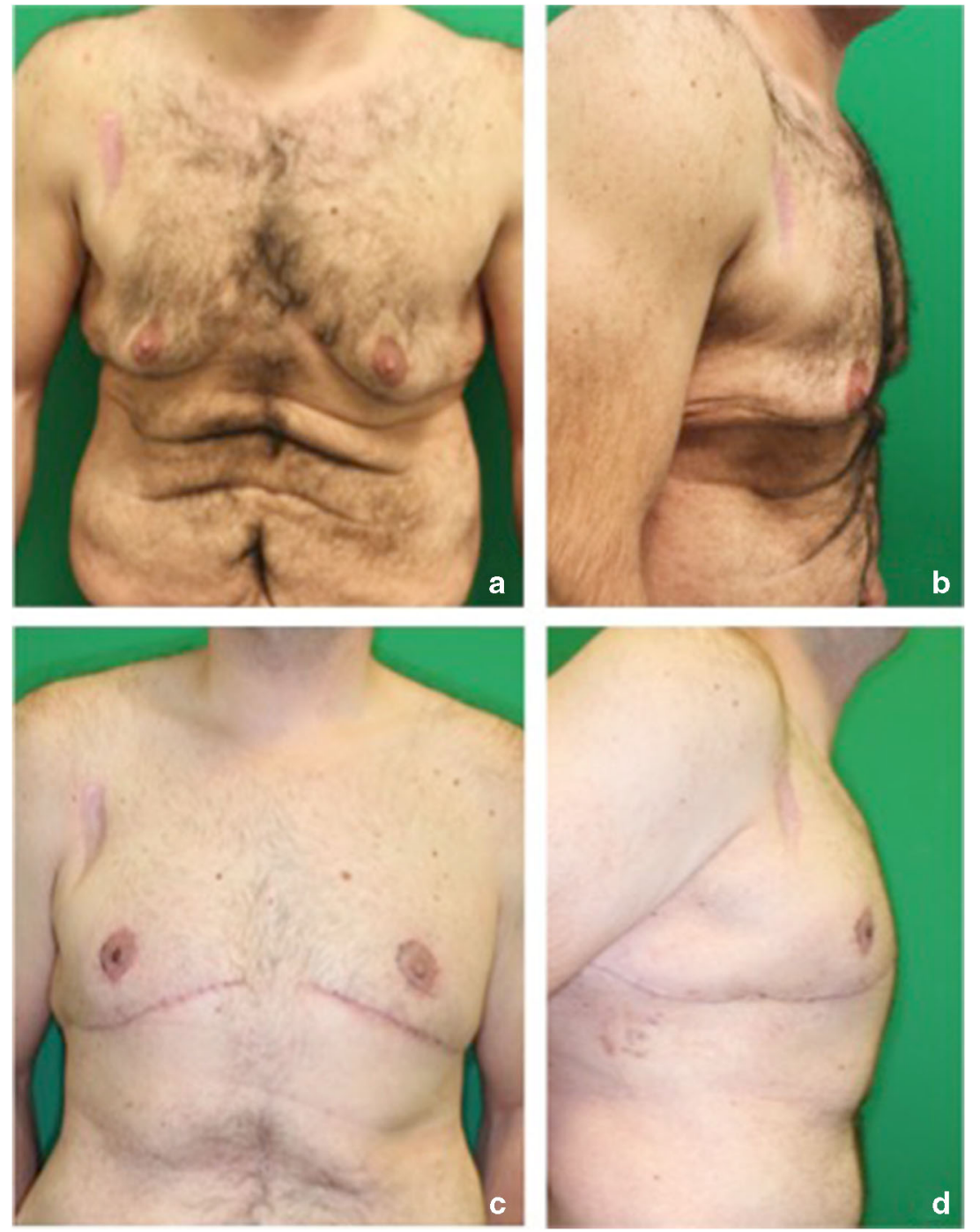

were requested by men [1]. Hence, the study's volume is due to the low percentage of gynaecomastias regarding all patients in the field of plastic surgery. As our clinics serve the entire spectrum of plastic surgery, hand surgery and burn care the presented caseload is representative.

Due to the study design we only had a very short time of follow up as the data were taken from the routine documentation of the clinical system and patient charts. Although the treatment of gynaecomastia is usually covered by the national health insurance in Germany, long term controls are not implemented in the local health care system. Therefore, a quality of life assessment could not be included in this study. However, the recent evaluation of KasielskaTrojan et al. showed significant improvement in all quality
Fig. 7 Examples of unpleasant results using a periareolar pexy (PAP) on the left or an inverted tscar approach on the right for gynaecomastia treatment in the first and second periods. Scars tend to widen due to the applied tension during PAP or provoke a distortion of the NAC due to the unnecessary vertical scar
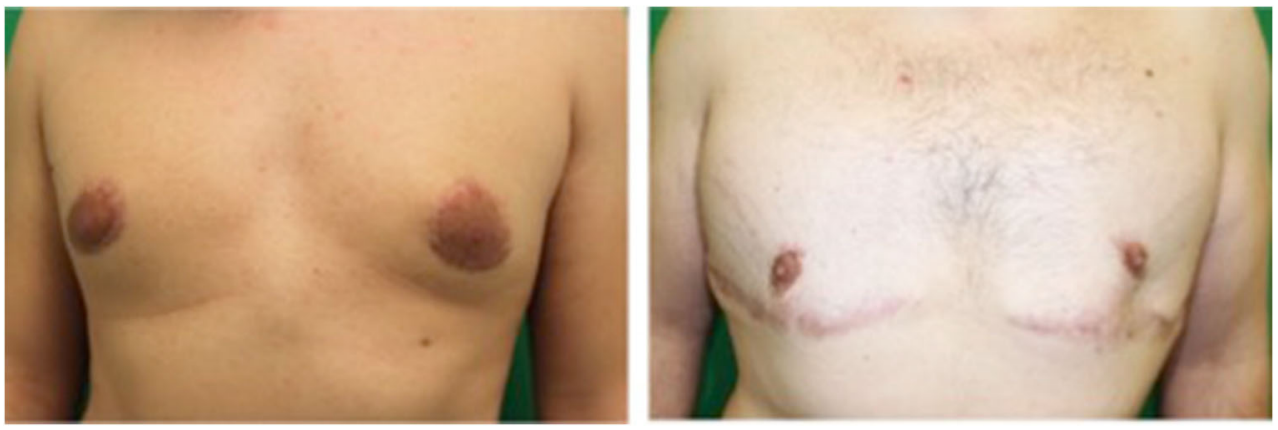
Table 1 During 4-year intervals the change of the used techniques can be seen

\begin{tabular}{|c|c|c|c|}
\hline & $\begin{array}{l}\text { 1st period } \\
\text { March } 2006 \text { to March } 2010\end{array}$ & $\begin{array}{l}\text { 2nd period } \\
\text { April } 2010 \text { to March } 2014\end{array}$ & $\begin{array}{l}\text { 3rd period } \\
\text { April } 2014 \text { to March } 2018\end{array}$ \\
\hline \multicolumn{4}{|l|}{ Technique $(n)$} \\
\hline Lipo & 0 & 6 & 3 \\
\hline $\mathrm{SCM}$ & 19 & 16 & 22 \\
\hline SCM + Lipo & 21 & 35 & 9 \\
\hline PAP & 1 & 1 & 2 \\
\hline PAP + Lipo & 12 & 3 & 0 \\
\hline SCM inv. T & 1 & 0 & 0 \\
\hline $\mathrm{SCM}+\mathrm{iScar}$ & 0 & 6 & 7 \\
\hline SUM & 54 & 67 & 43 \\
\hline OR time mean (min) & 113.5 & 106.7 & 123.6 \\
\hline Days of stay (days) & 3.7 & 3.5 & 3.2 \\
\hline \multicolumn{4}{|l|}{ Complications } \\
\hline \multicolumn{4}{|l|}{ Major $(n)$} \\
\hline Postop. bleeding & 0 & 0 & 3 \\
\hline \multicolumn{4}{|l|}{ Minor $(n)$} \\
\hline NAC necrosis & 0 & 2 & 0 \\
\hline Infection & 1 & 1 & 0 \\
\hline Iatrogen. burn & 1 & 0 & 0 \\
\hline \multicolumn{4}{|l|}{$\begin{array}{l}\text { Corrective revisions } \\
\quad(n)\end{array}$} \\
\hline Lipo & 0 & 3 & 2 \\
\hline $\mathrm{SCM}$ & 1 & 1 & 1 \\
\hline SCM + Lipo & 0 & 0 & 1 \\
\hline PAP + Lipo & 0 & 1 & 0 \\
\hline
\end{tabular}

The results show that procedures with unpleasant and excessive scars like periareolar pexies (PAP) and inverted T (inv. T) approaches have been abandoned in favour of combinations of ultrasound-assisted liposuction (UAL) with subcutaneous mastectomy (SCM) or breast reductions with an inferior single scar approach (iScar). No relevant change of the mean operation room $(\mathrm{OR})$ time, revisions or days of hospitalisation could be found. Major complications needing operative revisions occurred only in the $3 \mathrm{rd}$ period. Minor complications as nipple-areola complex (NAC) necrosis and soft tissue infections have been found in the 1st and 2nd period in comparable rates. Corrective revisions due to unfavourable results or recurrence are shown in the last section without significant differences over the 3 periods of life aspects in each of her 50 patients [37]. This supports our goal to offer effective treatments with minimal aesthetic impairment through scars.

\section{Conclusion}

Following the goal of plastic surgery to restore function, form and aesthetics a change of techniques an adoption of techniques that reduce scars and secondary surgery with improved aesthetic appearance was implemented in our daily routine in the last two decades. Breast surgery of male patients demands distinct considerations to use standardised, scar sparing and effective methods that clearly differ from approaches for women. We recommend a stage adopted technique avoiding extensive and aesthetically unpleasant scars. Gynaecomastias of grade 1 to $2 \mathrm{~b}$ are the domain of subcutaneous mastectomy combined with ultrasound-assisted liposuction. Higher degrees should be treated with a single horizontal scar in the submammary fold using an inferior pedicle or free nipple graft (Fig. 1).

Funding Information Open Access funding provided by Projekt DEAL.

\section{Compliance with ethical standards}

Conflict of interest The authors declare that they have no conflict of interest.

Ethical approval The study was approved by the clinical ethics committee of the Hannover Medical School (No. 8191 BO K 2018).

Informed consent Informed consent for the use of data and photographs for scientific purposes and publication in scientific journals was given by each patient. The study conforms to the provisions in accordance with the Helsinki Declaration (revised in 2013). 
Open Access This article is licensed under a Creative Commons Attribution 4.0 International License, which permits use, sharing, adaptation, distribution and reproduction in any medium or format, as long as you give appropriate credit to the original author(s) and the source, provide a link to the Creative Commons licence, and indicate if changes were made. The images or other third party material in this article are included in the article's Creative Commons licence, unless indicated otherwise in a credit line to the material. If material is not included in the article's Creative Commons licence and your intended use is not permitted by statutory regulation or exceeds the permitted use, you will need to obtain permission directly from the copyright holder. To view a copy of this licence, visit http://creativecommons.org/licenses/by/4.0/.

\section{References}

1. Surgeons ASoP (2017) Plastic Surgery Statistics Report 2017. https://wwwplasticsurgeryorg/documents/News/Statistics/2017/ plastic-surgery-statistics-full-report-2017pdf ASPS National Clearinghouse of Plastic Surgery Procedural Statistics

2. McKiernan JF, Hull D (1981) Breast development in the newborn. Arch Dis Child 56(7):525-529

3. Carlson HE (1980) Gynecomastia. N Engl J Med 303(14):795-799

4. Georgiadis E, Papandreou L, Evangelopoulou C, Aliferis C, Lymberis C, Panitsa C, Batrinos M (1994) Incidence of gynaecomastia in 954 young males and its relationship to somatometric parameters. Ann Hum Biol 21(6):579-587

5. Niewoehner CB, Nuttal FQ (1984) Gynecomastia in a hospitalized male population. Am J Med 77(4):633-638

6. Nuttall FQ (1979) Gynecomastia as a physical finding in normal men. J Clin Endocrinol Metab 48(2):338-340

7. Nydick M, Bustos J, Dale JH Jr, Rawson RW (1961) Gynecomastia in adolescent boys. JAMA 178:449-454

8. Sher ES, Migeon CJ, Berkovitz GD (1998) Evaluation of boys with marked breast development at puberty. Clin Pediatr 37(6):367-371

9. Williams MJ (1963) Gynecomastia. Its incidence, recognition and host characterization in 447 autopsy cases. Am J Med 34:103-112

10. Fentiman IS, Fourquet A, Hortobagyi GN (2006) Male breast cancer. Lancet 367(9510):595-604

11. Staerkle RF, Lenzlinger PM, Suter SL, Varga Z, Melcher GA (2006) Synchronous bilateral ductal carcinoma in situ of the male breast associated with gynecomastia in a 30-year-old patient following repeated injections of stanozolol. Breast Cancer Res Treat 97(2):173-176

12. Giordano SH, Cohen DS, Buzdar AU, Perkins G, Hortobagyi GN (2004) Breast carcinoma in men: a population-based study. Cancer 101(1):51-57

13. Alagaratnam TT (1987) Idiopathic gynecomastia treated with tamoxifen: a preliminary report. Clin Ther 9(5):483-487

14. Khan HN, Rampaul R, Blamey RW (2004) Management of physiological gynaecomastia with tamoxifen. Breast 13(1):61-65

15. Mannu GS, Sudul M, Bettencourt-Silva JH, Tsoti SM, Cunnick G, Ahmed SF (2018) Role of tamoxifen in idiopathic gynecomastia: a 10-year prospective cohort study. Breast J. https://doi.org/10.1111/ tbj. 13080

16. Webster GV (1944) Gynecomastia in the Navy. Military Surgeon 95(5):375-379

17. Simon BE, Hoffman S, Kahn S (1973) Classification and surgical correction of gynecomastia. Plast Reconstr Surg 51(1):48-52

18. Kornstein AN, Cinelli PB (1992) Inferior pedicle reduction technique for larger forms of gynecomastia. Aesthet Plast Surg 16(4):331-335

19. Benelli L (1990) A new periareolar mammaplasty: the "round block" technique. Aesthet Plast Surg 14(2):93-100
20. Steele SR, Martin MJ, Place RJ (2002) Gynecomastia: complications of the subcutaneous mastectomy. Am Surg 68(2):210-213

21. Mett TR, Krezdorn N, Luketina R, Boyce MK, Henseler H, Ipaktchi R, Vogt PM (2017) Optimal positioning of the nippleareola complex in men using the Mohrenheim-estimatedtangential-tracking-line (METT-line): an intuitive approach. Aesthet Plast Surg 41(6):1295-1302

22. (1846) AP On male breast resembling the female. In: Adams F (Hrsg) The seven books of Paulus Aegineta. Book 6 Bd 2 (Section 46):334-335

23. Innocenti A, Melita D, Mori F, Ciancio F, Innocenti M (2017) Management of Gynecomastia in patients with different body types: considerations on 312 consecutive treated cases. Ann Plast Surg 78(5):492-496

24. Heymans O, Castus P, Grandjean FX, Van Zele D (2006) Liposuction: review of the techniques, innovations and applications. Acta Chir Belg 106(6):647-653

25. Rohrich RJ, Ha RY, Kenkel JM, Adams WP Jr (2003) Classification and management of gynecomastia: defining the role of ultrasound-assisted liposuction. Plast Reconstr Surg 111(2): 909-923; discussion 924-905

26. Rohrich RJ, Beran SJ, Kenkel JM, Adams WP Jr, DiSpaltro F (1998) Extending the role of liposuction in body contouring with ultrasound-assisted liposuction. Plast Reconstr Surg 101(4):1090 1102 discussion 1117-1099

27. Bailey SH, Guenther D, Constantine F, Rohrich RJ (2016) Gynecomastia management: an evolution and refinement in technique at UT Southwestern Medical Center. Plastic and reconstructive surgery. Glob Open 4(6):e734

28. Lee YK, Lee JH, Kang SY (2018) Gynecomastia: glandularliposculpture through a single transaxillary one hole incision. J Plast Surg Hand Surg 52(2):117-125

29. Innocenti A, Melita D, Innocenti M (2018) Evaluation of glandular liposculpture as a single treatment for grades i and ii gynecomastia. Aesthet Plast Surg 42:1707-1708

30. Tebbetts JB (2013) A process for quantifying aesthetic and functional breast surgery: I. quantifying optimal nipple position and vertical and horizontal skin excess for mastopexy and breast reduction. Plast Reconstr Surg 132(1):65-73

31. Finckenstein JG, Wolf H (2006) Chest lifting. Aesthet Plast Surg 30(3):286-293

32. Hurwitz DJ (2015) Boomerang pattern correction of gynecomastia. Plast Reconstr Surg 135(2):433-436

33. Thienot S, Bertheuil N, Carloni R, Meal C, Aillet S, Herlin C, Watier E (2017) Postero-inferior pedicle surgical technique for the treatment of grade III gynecomastia. Aesthet Plast Surg 41(3):531-541

34. Gusenoff JA, Coon D, Rubin JP (2008) Pseudogynecomastia after massive weight loss: detectability of technique, patient satisfaction, and classification. Plast Reconstr Surg 122(5):1301-1311

35. Zavlin D, Jubbal KT, Friedman JD, Echo A (2017) Complications and outcomes after gynecomastia surgery: analysis of 204 pediatric and 1583 adult cases from a national multi-center database. Aesthet Plast Surg 41(4):761-767

36. Fricke A, Lehner GM, Stark GB, Penna V (2018) Gynecomastia: histological appearance in different age groups. J Plast Surg Hand Surg 52(3):166-171

37. Kasielska-Trojan A, Antoszewski B (2017) Gynecomastia surgeryimpact on life quality: a prospective case-control study. Ann Plast Surg 78(3):264-268

Publisher's note Springer Nature remains neutral with regard to jurisdictional claims in published maps and institutional affiliations. 